\title{
Violência e maus tratos contra a pessoa idosa: representações sociais de jovens, adultos e idosos
}

\author{
Violence and abuse against the elderly: social representations of young people, adults and the elderly \\ Violencia y maltrato contra la persona mayor: representaciones sociales de jóvenes, adultos y ancianos
}

\author{
Ana Karênina de Freitas Jordão do Amaral', Maria Adelaide Silva Paredes Moreira", Maria Adriana Coler"', \\ Maria do Socorro Costa Feitosa Alves'v, Felismina Rosa Parreira Mendesv , Antonia Oliveira Silva ${ }^{\text {vl }}$
}

\begin{abstract}
RESUMO
Objetivo: analisar as representações sociais sobre violência e maus tratos contra a pessoa idosa, construídas por jovens, adultos e idosos. Método: estudo exploratório de abordagem qualitativa, utilizando o aporte teórico das representações sociais, realizado com 150 participantes, escolhidos aleatoriamente, no período de março/setembro de 2015. Dados foram coletados por entrevista semiestruturada utilizando estímulos indutores: violência e maus tratos contra pessoa idosa. O material empírico foi organizado em dois corpora e processados com o auxílio do software IRaMuTe ${ }^{\circledR}$. Os dados processados apontaram para o estimulo violência três classes semânticas; para maus tratos, duas classes. O projeto foi aprovado em Comitê de ética e pesquisa (protocolo 0516/14). Resultados: jovens falam de tipos de violência; adultos falam sobre contravenções relacionadas; idosos associam dimensões de cunho afetivo. Conclusão: espera-se que os achados contribuam para dimensionamento de ações educativas-protetivas para efetivação de políticas públicas ao idoso.

Descritores: Idoso; violência; maus-tratos; saúde.
\end{abstract}

\section{ABSTRACT}

Objective: to examine social representations constructed by young people, adults and the elderly regarding violence and abuse against older people. Method: this exploratory, qualitative study used social representations theory in the period from March to September 2015 with 150 randomly chosen participants. Data were collected by semi-structured interview using two stimulus-terms: violence and abuse against elderly persons. The empirical material was organized into two corpuses and processed with IRaMuTeQ ${ }^{\circledR}$ software. The processed data pointed to three semantic classes for the stimulus-term violence, and two for the stimulus-term abuse. The project was approved by the research ethics committee (Protocol 0516/14). Results: younger participants mentioned types of violence; adults talked about violence-related offenses; and the elderly associated violence and abuse with dimensions of affect. Conclusion: it is hoped that the findings will contribute to scaling educational and protective actions for effective application of policies for the elderly. Descriptors: Old man; violence; mistreatment; health.

\section{RESUMEN}

Objetivo: analizar las representaciones sociales sobre violencia y maltrato contra la persona mayor, construidas por jóvenes, adultos y ancianos. Método: estudio exploratorio de enfoque cualitativo, utilizando el aporte teórico de las representaciones sociales, realizado con 150 participantes, elegidos al azar, en el período de marzo / septiembre de 2015. Los datos fueron recolectados por entrevista semiestructurada utilizando estímulos inductores: violencia y maltrato contra el anciano. El material empírico fue organizado en dos corpus y procesado con la ayuda del software IRaMuTeQ ${ }^{\circledR}$. Los datos procesados apuntaron hacia el estímulo violencia, tres clases semánticas; hacia maltratos, dos clases. El proyecto fue aprobado en el Comité de ética e investigación (protocolo 0516/14). Resultados: jóvenes hablan sobre tipos de violencia; los adultos hablan sobre contravenciones relacionadas; los ancianos asocian dimensiones de carácter afectivo. Conclusión: se espera que los hallazgos contribuyan a dimensionar acciones educativas-protectoras para volver efectivas las políticas públicas en cuanto al anciano.

Descriptores: Ancianos; violencia; malos tratos; salud.

\section{INTRODUÇÃO}

Sabe-se que o envelhecimento da população é um fenômeno mundial. No Brasil existem mais de 20 milhões idosos, correspondendo a cerca de $11 \%$ da população. Projeções indicam que esse percentual deve triplicar em 40 anos e, para garantir o envelhecimento dessas pessoas de forma saudável e equilibrada, com dignidade, e sem opressão, é preciso trabalhar intensamente na prevenção da violência ${ }^{1,2}$.

'Fonoaudióloga. Doutora. Professora Adjunta. Universidade Federal da Paraíba. Paraíba, Brasil. E-mail: akfjafono@hotmail.com

"Fisioterapeuta. Doutora. Professora Adjunta. Universidade Federal da Paraíba. Paraíba, Brasil. E-mail: jpadelaide@hotmail.com

'"Enfermeira. Doutora. Universidade de Bridgeport. Bridgeport, Estados Unidos. E-mail: mfcoler@gmail.com

IVEnfermeira. Doutora. Professora Titular. Universidade Federal do Rio Grande do Norte. Rio Grande do Norte, Brasil. E-mail: socorrocfa@hotmail.com

vEnfermeira. Doutora. Professora. Universidade de Évora. Évora, Portugal. E-mail: fm@uevora.pt

v'Enfermeira. Doutora. Professora Titular. Universidade Federal da Paraíba. Paraíba, Brasil. E-mail: alfaleda2@gmail.com

viIIntegra o projeto internacional: Violência contra idosos em diferentes grupos etários: um estudo de representações sociais, que está sendo realizado no Brasil, 
O envelhecimento populacional mudará o perfil da população mundial nos próximos anos e requererá diferentes olhares que envolvem aspectos sociais, culturais, econômicos e afetivos associados diretamente com a qualidade de vida dessa população $0^{3,4}$. Salienta-se que o processo de envelhecimento vem normalmente acompanhado de um declínio das funções gerais em que a função motora é certamente comprometida ${ }^{2,5}$.

A violência contra a pessoa idosa é problema sério, que a sociedade precisa enfrentar e combater. Idosos têm sido vítimas dos mais diversos tipos de maus tratos, que podem vir em forma de insultos e espancamentos pelos próprios familiares/cuidadores, até os desrespeitos sofridos em transportes públicos e instituições públicas ou privadas. De acordo com a Lei no 12.461 , de 26 de julho de $2011^{6}$, considera-se violência contra o idoso como uma ação/omissão praticada em local público ou privado que cause morte, dano ou sofrimento físico ou psicológico ${ }^{7,8}$.

A Organização Mundial de Saúde define violência como utilização proposital da força física ou autoridade, concreta ou por coação, contra si mesmo, outra pessoa, grupo ou comunidade. O termo maus tratos seria, pois, considerado uma forma de violência e pode ser classificado por: maus tratos às crianças, violência juvenil, violência praticada por parceiro íntimo, violência sexual e abuso de idosos $^{9}$. No tocante a violência contra a pessoa idosa e suas manifestações há necessidade de uma atenção especial por constituir barreiras frente à igualdade de direitos ${ }^{10}$.

Neste contexto, questiona-se: quais as representações sociais sobre violência e maus tratos para jovens, adultos e idosos? Assim, conhecer o que pensam pessoas de diferentes grupos etários sobre violência e maus tratos contra a pessoa idosa delimita o objeto de estudo. Logo, este estudo teve o objetivo de analisar as representações sociais sobre violência e maus tratos contra a pessoa idosa, construídas por jovens, adultos e idosos.

\section{REFERENCIAL TEÓRICO}

A violência contra a pessoa idosa é considerada problema de saúde pública, tanto pela sua magnitude quanto pelo impacto político, social, econômico, cultural, capaz de influir negativamente na qualidade de vida e interferir para que se tenha uma vida saudável e plena. Gera consequências à pessoa que envelhece e suas famílias e comunidades, demandando um aumento nos serviços assistenciais de saúde em nível mundial2,11,12. Embora com inúmeras políticas públicas existentes no Brasil, ainda é tímida a concretização de ações singulares para resolutividade frente à violência contra este grupo ${ }^{13,14}$.

Sabe-se que é preocupante a problemática da violência contra idosos em nível mundial do ponto de vista social, político e cultural. Este tema constitui um importante objeto de investigação, cujos achados podem contribuir para adoção de práticas de saúde e ações protetivas contextualizadas socialmente, para atender necessidades singulares de grupos sociais específicos, a partir de formas de conhecimentos socialmente compartilhados capazes de definirem tipos de necessidades na prevenção e no enfrentamento da violência, e assim colaborar de forma singular com as políticas públicas e de saúde direcionadas às vítimas. Neste sentido, o envelhecimento traz profundas e diferentes mudanças populacionais, e pode ser analisado em múltiplas dimensões: sociabilidade, as relações entre as gerações, às transmissões materiais e afetivas, diferentes formas de violência e o asilamento, entre outros ${ }^{15}$.

Tal complexidade se constitui um território fecundo a ser investigado que se engendra na interface envelhecimento/violência e suas repercussões na saúde e na qualidade de vida da pessoa idosa. Aponta à necessidade de se investigar dimensões subjetivas da violência contra o idoso, em que diferentes áreas do saber, em particular a saúde, podem ganhar visibilidade pela oportunidade de mediação ao oferecer um cuidar humano integral.

Surge a necessidade de questionamentos sobre o envelhecimento na interface com a violência, capazes de favorecer espaços de diálogo envolvendo a vivência individual da pessoa idosa no cotidiano profissional em saúde ressaltando as consequências dos diferentes tipos de violências sofridas. Optou-se por trabalhar dimensões subjetivas do envelhecimento e violência contra idosos por ser tão grave quanto a violência vivida por crianças.

Este estudo é subsidiado no aporte teórico das representações sociais enquanto uma modalidade de conhecimento particular que tem como função elaborar comportamentos e a comunicação entre as pessoas de determinados grupos sociais. Permite que se analise a inserção social das pessoas e do referido grupo na tomada de posição frente ao objeto de representação, caracterizando uma importante dimensão das representações sociais - as práticas e comportamentos ${ }^{16}$.

Sabe-se da importância do saber informal compartilhado em grupos específicos sobre o que pensam da violência contra o idoso e das influências sociais da comunicação de seus integrantes no compartilhamento de ideias, valores, crenças. E que tal saber constitui realidades cotidianas, identificáveis a partir de aspectos psicossociológicos e culturais em um contexto sociocultural próprio de grande importância por definirem os comportamentos de seus membros ${ }^{17,18}$.

\section{MetodologiA}

Estudo exploratório de abordagem qualitativa realizado no município de João Pessoa/Paraíba/Brasil realizado com 150 participantes, escolhidos aleatoriamente, de ambos os sexos, inseridos no campus I da Universidade Federal da Paraíba e nas Unidades de Saúde da Família, distribuídos em três grupos etários: jovens (18 a 29 anos), adultos (30 a 59 anos) e idosos 
(60 anos ou mais). O Estado da Paraíba tem população idosa que ultrapassa 450 mil; João Pessoa possui cerca de 74 mil idosos, correspondendo a $16,53 \%$ dos idosos do estado, e é considerada a terceira cidade com maior número de idosos no Brasil ${ }^{1}$.

Todos os participantes do estudo foram informados sobre os objetivos e assinaram Termo de Consentimento Livre e Esclarecido. O projeto de pesquisa foi aprovado pelo Comitê de Ética em Pesquisa do Centro de Ciências da Saúde da Universidade Federal da Paraíba, sob protocolo 0596/14.

Os dados foram coletados no período de março/ setembro de 2015, a partir de entrevista semiestruturada, contemplando na primeira parte, o Teste da Associação Livre de Palavras com os termos indutores: violência e maus tratos contra pessoa idosa e na segunda parte foram considerados os dados sociodemográficos. Os dados foram dispostos em dois corpora.

Os corpora correspondentes ao material textual foram organizados com o auxílio dos softwares Open Office 4.0.0, e pelo software de Análise Textual IRaMuTe ${ }^{\circledR}$ que procurou identificar e organizar os segmentos de texto (ST) correspondentes a cada corpus referentes aos estímulos indutores, revelandose aproximações e oposições das modalidades na construção dos fatores a partir da Classificação Hierárquica Descendente $(\mathrm{CHD})^{19-21}$. Nesta etapa ocorre a classificação dos ST, segundo seus vocábulos em que este conjunto é repartido tomando por base a frequência de ocorrência das formas reduzidas (palavras já lematizadas). A partir desta etapa ocorre a análise em matrizes onde o software estrutura os dados em representação gráfica denominada de dendograma da CHD. Esta esclarece relações entre classes segundo o vocabulário léxico característico e as variáveis distintas. Tais classes são compostas por vários ST em função de uma classificação segundo a distribuição de seu vocabulário capaz de indicar possíveis representações sociais/campos de imagens sobre temas relacionados com os corpora analisados ${ }^{20,21}$.

\section{RESUltados E Discussão}

Dos 150 participantes do estudo, 75 são homens e 75 são mulheres, sendo que $52(34,7 \%)$ afirmam ser casados(as), 49 (32,7\%) solteiros(as), 21 (14\%) viúvos(as) e 11 (7,3\%) divorciados(as); 109 (72,7\%) informam ter filhos; $37(24,7 \%)$ residem com outro(s) membro(s) da família, 31(20,7\%) com esposo(a) e filho(a), 28 (18,7\%) residem com pai e/ou mãe, 26 (17,3\%) com esposo(a) ou companheiro(a); 57 (38\%) possuem ensino médio completo; 71(47,3\%) afirmam ser empregados, 38 (25,3\%) são aposentados e 25 (16,7\%) são estudantes; 81 (54\%) são profissionais de serviços.

Os dados do Teste de Associação Livre de Palavras foram estruturados em: um corpus de violência, no qual se obteve uma CHD que reteve $138 \mathrm{ST}$, com aproveitamento de $92 \%$, compondo três classes de respostas dos voluntários do estudo; e para o corpus de maus tratos, obteve-se uma CHD de 124 ST com aproveitamento de $82,67 \%$, organizadas em duas classes de respostas dos participantes.

As classes foram organizadas em dendogramas, ilustrando as relações entre as mesmas e com a descrição de cada, sobretudo, pelo vocabulário léxico de seus ST e suas variáveis. À luz da Teoria de Representações Sociais, estas classes podem indicar conhecimentos do senso comum ou campos de imagens sobre o dado objeto ${ }^{18,22}$.

\section{Sentidos associados à violência}

Os dados obtidos para o estímulo violência apontaram três classes semânticas e estas consistem nas diferenças entre os conteúdos das mesmas. Podem ser observadas na figura 1.

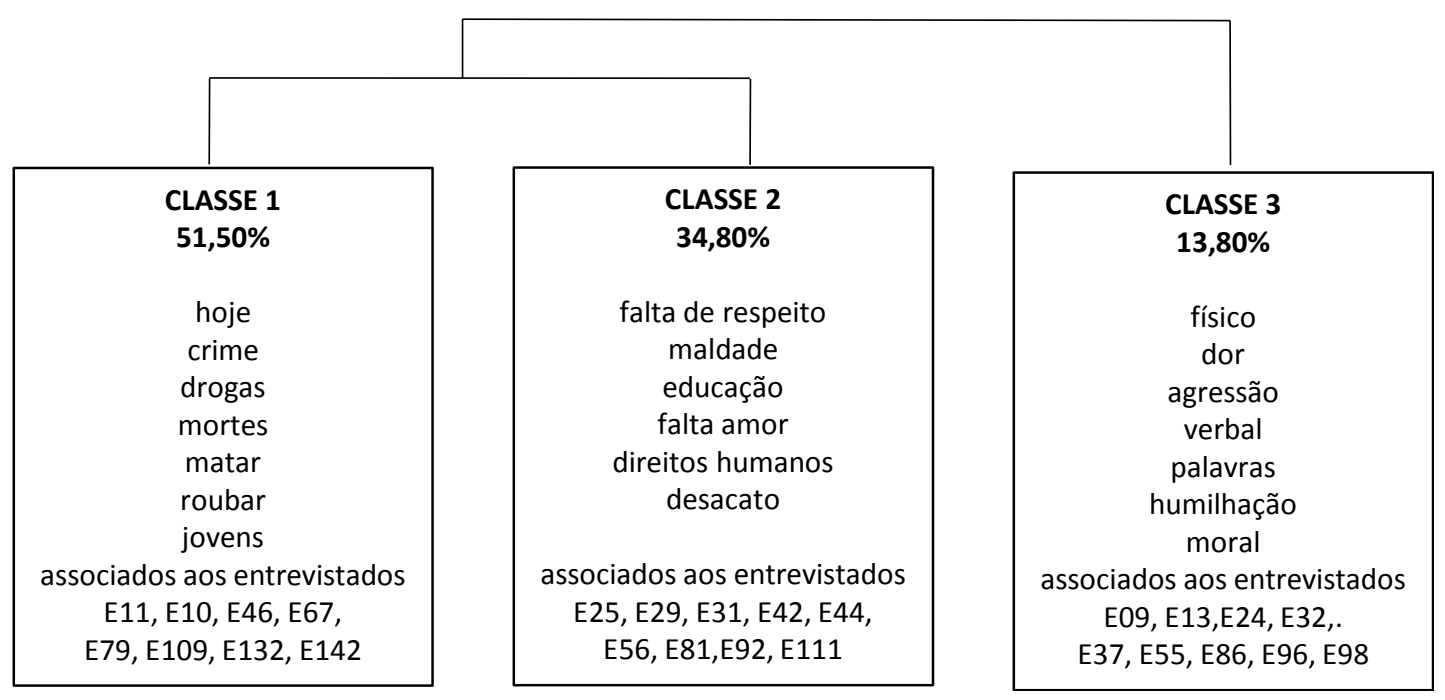

FIGURA 1: Dendograma da CHD com conteúdos sobre violência contra a pessoa idosa. João Pessoa, PB, 2016. 


\section{Classe 3 - tipos de violência}

Colaborou na formação desta classe, participantes jovens, com 13,8\% dos ST que descrevem a violência como um ato físico que causa dor sob a forma de agressão verbal com palavras que tem o intuito de causar humilhação ou de efeito moral à pessoa idosa.

Tais conteúdos são exemplificados por:

[...] agressão física ou verbal é o estopim de um ato violento, representa um total desequilibrio por parte de quem a pratica [...] tem muito tipo de agressão àquela física e a verbal também [...] só tem dor na violência [...] dor, além da física compreende a dor psicológica [...] a agressão pode ser física ou moral [...] qualquer tipo de violência causa dor, seja física ou emocional [...] agressão física ou moral a violência invade do espaço do outro sem sua permissão [...] as palavras também machucam muito [...] humilhar também é violência [...] (E9, E16, E24, E32, E37, E39, E40, E41, E48).

\section{Classe 1 - descrições sobre atos criminosos}

Esta classe é formada por 71 ST $(51,5 \%)$ do conjunto de respostas, constituindo a maior classe com maior frequência de ocorrência. Os conteúdos mostram que para os adultos hoje é considerado crime o uso de drogas que podem causar mortes ou levar alguém a matar ou roubar, cometido ou sofrido por jovens. Essa classe apresenta noções centrais atuais sobre violência veiculadas na mídia e que estão em destaque pela repercussão social.

[...] lembro dos crimes que passam na televisão [...] hoje em dia as pessoas brigam por tudo, vivem agredindo por besteira [...] os jovens querem se drogar e roubar, não querem estudar [...] os crimes que passam na televisão são de uma brutalidade enorme, causam medo [...] as drogas são um pivô importante para a violência [...] não se rouba por necessidade de comer, é para usar drogas [...] drogas é o que vem acabando com nossos jovens e causando violência [...] (E51, E58, E63, E67, E79, E81, E90, E93).

\section{Classe 2: Motivações para violência}

Com $34,8 \%$ dos ST esta classe evidencia que os idosos associam violência à falta de respeito ou maldade por conta da educação ou da falta de amor indicando como responsável os direitos humanos e consideram o desacato como uma forma de violência.

[...] toda violência é controlada por injustiça [...] é através do desacato e falta de respeito que começa a surgir a violência [...] a violência se caracteriza pela falta de respeito para com o outro [...] a violência acontece pela falta de amor ao próximo [...] a falta de amor está em todo canto, dentro de casa, na rua, e isso leva à violência [...] violência vem sempre relacionada com desrespeito aos direitos humanos de alquém[...] a educação que não tivemos pode gerar a violência [...] violência lembra maldade das pessoas [...] falta educação nesse país, a educação é um dos mais importantes fatores que contribuem para a violência [...] (E101, E103, E111, E123, E134, E142, E144, E146, E150).

\section{Sentidos associados aos maus tratos}

Os dados obtidos para o estímulo maus tratos apontaram duas classes semânticas e estas consistem nas diferenças entre os conteúdos ou vocabulários dos ST sobre o estímulo maus tratos, apresentadas na figura 2.

\section{Classe 1: vulnerabilidade aos maus tratos}

A classe é formada por 64 ST $(51,6 \%)$ onde evidencia que para os jovens e adultos o idoso é uma pessoa sem defesa, debilitada e que geralmente vive sozinha ou é abandonada, frágil, indefesa:

[...] é uma covardia o idoso não sabe se defender [...] muitas vezes não há chance de defesa [...] o idoso já é debilitado vem outro e faz mal [...] pessoa idosa não tem como se defender [...] as pessoas esquecem que vão envelhecer e que vão querer no futuro serem bem tratadas [...] idoso muitas vezes necessita de cuidados e encontra-se sozinho [...] não se maltrata o indefeso, é muita crueldade não deve ter perdão [...] maltratar uma pessoa idosa é não respeitar o que ela represente. (E01, E07, E28, E38, E51,E60, E75, E86, E93).

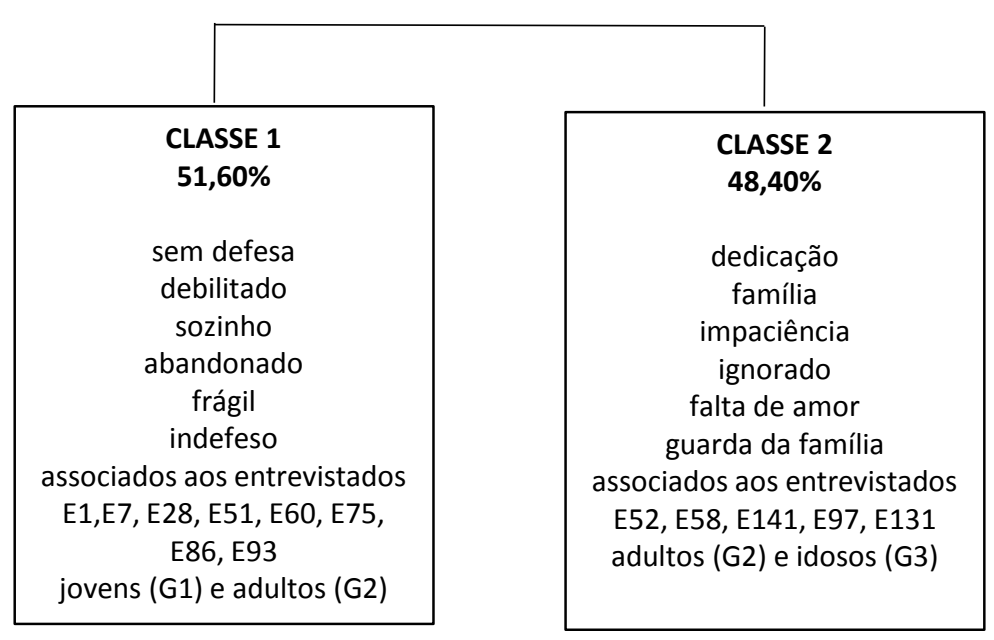

FIGURA 2: Dendograma da CHD com conteúdos semânticos sobre maus tratos contra a pessoa idosa. João Pessoa, PB, 2016. 


\section{Classe 2: descrições sobre maus tratos familiares}

Com 60 ST (48,4\%), esta classe contempla as falas de adultos e idosos sobre descrições frente as situações de maus tratos verbalizados sobre a pessoa idosa. Os participantes afirmam que a pessoa idosa teve uma vida de dedicação à família e na velhice a família demonstra impaciência sendo, inclusive, ignorado, vivendo triste pela falta de amor e submetido a guarda da família:

[...] falta de respeito para aqueles que dedicaram a vida aos seus familiares [...] é um crime que consiste em submeter uma pessoa sob sua guarda [...] falta de amor da família gera todo tipo de maus tratos [...] acredito que a maioria dos maus tratos surge do abandono e da impaciência para quem o idoso se dedicou [...] indivíduo é ignorado pela família e passa a sofrer danos psicológicos que é um dos danos mais prejudiciais à saúde [...] (E52, E58, E141, E97, E131).

O perfil dos participantes do estudo reflete a realidade de João Pessoa, na região Nordeste do Brasil. É o principal centro financeiro e econômico do estado, sendo a quinta cidade mais populosa da região. A população idosa da cidade é composta, em sua maioria, por mulheres em todas as faixas, ou seja, a cada cinco anos (60-64/65-69/70-74/75-79/80) ou mais ${ }^{1}$. E, apesar de já apresentar alto índice de violência, ainda é considerada uma das capitais com melhor qualidade de vida ${ }^{1,2}$.

Questões culturais permeiam as sociedades e, comumente, preconceito e discriminação são formas antigas e frequentes de violência contra a pessoa idosa. Nos mais diferentes contextos socioculturais, jovens e adultos apresentam uma tendência a desvalorizá-los e tratá-los como descartáveis, inúteis e sem função social $^{23}$. Estes tipos de comportamentos tendem a estimular o idoso à depressão, isolamento e, em alguns casos, a autonegligência, culminando com desejo de morte ${ }^{24,25}$. Outros estudos têm demonstrado aspectos semelhantes no que diz respeito a tendência de uma cultura de naturalização à violência contra a pessoa idosa e à violação de seus direitos ${ }^{2,10}$.

Estudo sobre violência contra pessoa idosa com perfil sócio demográfico semelhante foi realizado em outra cidade do Brasil ${ }^{25}$. A amostra não é estratificada por sexo e idade, o que dificulta a possibilidade de comparação. Não obstante, os dados apontam uma participação maior das mulheres em pesquisas científicas.

No tocante aos achados para o estimulo violência na Classe 3 - tipos de violência - observa-se representações sociais mais associadas aos tipos de violência preferencialmente por jovens. É nítida a compreensão de que a violência não é apenas física; as representações sociais dos participantes associados às diferentes formas de falar com a pessoa idosa referem humilhação e atitudes grosseiras. Vários estudos demonstram o sofrimento mental em forma de humilhação e que atitudes rudes para falar são capazes de provocar processos autodestrutivos, por vezes levando a tentativa de suicídio ${ }^{2,24}$. Em pesquisa realizada em Camaragibe ( $\mathrm{PE})$, por exemplo, foi encon- trado um dos índices mais altos de queixa de violência psicológica por idosos através do Disque denúncia ${ }^{26}$.

No que se refere à Classe 1 - descrições sobre atos criminosos- pode-se encontrar representações sociais associadas às contravenções/infrações que poderiam estar diretamente relacionadas à violência contra o idoso. Estudos apontam uso de álcool ou outras drogas como fator de risco para violência ${ }^{25,27,28}$ e tais fatores foram os mais evocados pelos participantes adultos. Relatos vinculam uso de álcool ou outras drogas aos crimes que são noticiados diariamente e que geram violência também dentro de casa. Nesse contexto, estão os idosos que convivem com várias gerações, como encontrado em nossa amostra ( $96 \%$ dos 50 participantes). Evidenciam um conhecimento de que existe algo que cause ou provoque a possibilidade de violência dentro da residência do idoso. A questão da droga que envolve o dinheiro que se tira do idoso, que o agride para conseguir o que deseja (as drogas), foi conteúdo bastante evocado pelos adultos.

A Organização Mundial de Saúde, em relatório sobre prevenção da violência, determina a redução à disponibilidade do uso nocivo do álcool como uma das estratégias para prevenção da violência ${ }^{2}$. Entretanto, ainda existem muitas dificuldades para a concreta implantação dessa e outras estratégias, principalmente pelo fato de que os planos de ação nem sempre são subsidiados por dados reais, que possam embasá-los adequadamente ${ }^{2,14}$.

A Classe 2 - motivações para a violência - refere-se a enunciações que se voltam à falta de amor e respeito, desrespeito aos direitos humanos, falta de educação que gera a violência, associadas em sua maior parte pelos idosos. Nessas proposições estão enraizados os três principais tipos de preconceito sobre a velhice que o desgaste do corpo distorce a realidade e leva a crença do envelhecimento como doença, que já gera a ideia de que o idoso é descartável, pois, não produz, e que se tornam um peso para os familiares, tidos, então, como um problema. As pessoas referem que sobrecarregam o cotidiano com múltiplas atividades para cuidar do idoso e percebe-se que não são preparados para compreender o processo de envelhecimento e despejam a exaustão/ esgotamento em atitudes agressivas. O idoso acaba mesmo se vendo como peso social 2,23,29.

A educação sobre e para o envelhecimento seria uma alternativa para minimizar/prevenir a questão da violência contra o idoso. Estratégias são apontadas dentro dessa perspectiva: apoio às famílias que cuidam de idoso e a formação de profissionais capacitados para orientar, tratar e encaminhar sempre que necessário ${ }^{2,12}$. Contudo, a modificação de crenças culturalmente estabelecidas precisa ser posta como ponto chave para mudar a questão do preconceito contra a velhice e contribuir com transformação de comportamentos possivelmente motivadores da violência.

Com relação aos maus tratos, na Classe 1 - vulnerabilidade dos maus tratos - são encontrados conteúdos 
dirigidos à pessoa idosa, vista como alguém frágil, que não sabe se defender, evocados por jovens e adultos. Os relatos rememoram o fato de que as pessoas esquecem que um dia também serão idosos, e que deveriam mudar este comportamento se quiserem ser bem tratadas no futuro. Esse achado remete à negação da velhice tão bem esclarecida por outros autores: representações sociais de que ninguém deseja ser velho, exatamente por conta de questões culturais já enraizadas que julgam o processo de envelhecimento como algo ruim, destrutivo $^{30}$. O jovem é tido como ideal de beleza e o idoso como alguém descartável ${ }^{31}$. Essa discriminação de idade não condiz com o fato de que a maioria da população idosa brasileira é saudável, ativa e trabalha (mesmo depois de aposentada), chefia família e contribui para sua própria manutenção².

Na Classe 2 de maus tratos - descrições sobre maus tratos familiares - são encontrados conteúdos associados aos conflitos familiares que tem relação com a violência contra o idoso dentro de casa, tendo sido evocados por mais adultos e idosos. Esses conflitos familiares são apontados em estudos como movidos por recursos financeiros, nos quais as pessoas da família tomam para si as propriedades e se tornam legalmente responsáveis por suas decisões ${ }^{12,32}$. Entretanto, mesmo em condições de decidir sobre seus recursos, muitos idosos são impedidos disso e se encontram em situação de abandono ou negligência².

No Brasil, apesar de ter se verificado queda em alguns índices como, por exemplo, o analfabetismo e a fome, passa há alguns anos, por uma recessão, com contração das atividades econômicas, queda do PIB, aumento de desemprego ${ }^{33,34}$. Passou a ser frequente, em todo o país, as pessoas se aproveitarem da fragilidade dos idosos, de forma a se apropriar dos bens, proventos, pensão, fazer retenção de cartão magnético bancário, com a finalidade de usufruir dos mesmos, e não em proveito dos idosos. Estão em crescimento, inclusive, consecutivos empréstimos em nome de pessoas idosas, comprometendo a sua renda².

Os conflitos familiares são representados pelos adultos e idosos na sua maior parte, como uma das causas da violência, já que o ignoram, negligenciam suas necessidades e revertem seus recursos para a família, principalmente nos casos de demenciados que precisam de cuidados e atenção mais especializada ${ }^{35-38}$.

\section{CONCLUSÃo}

Os grupos etários possuem experiências e convivência com indivíduos idosos. Os jovens evocaram mais os tipos de violência e tem consciência que a mesma não é apenas física; tem uma visão do quanto podem provocar prejuízos à qualidade de vida. Os adultos evocaram mais conteúdos relacionados às contravenções associadas à violência contra o idoso e aos conteúdos dirigidos ao idoso frágil, debilitado; relataram também conflitos fa- miliares como possíveis causas. Os idosos apresentaram uma visão mais ampliada do tema; são eles quem sofrem violência dos mais diversos tipos no cotidiano. Referiram a questão da dedicação à família e que depois de tantos anos sofrem com falta de amor e desrespeito.

\section{REFERÊNCIAS}

1. Brasil. Lei n. 12.461 , de 26 de julho de 2011. Altera a Lei $n^{\circ} 10741$ de 1ํ de outubro de 2003, para estabelecer a notificação compulsória dos atos de violência praticados contra o idoso atendido em serviço de saúde. Disponível em: http://planalto.gov.br/CCivil_03/_Ato20112014/2011/Lei/L12461.htm. Acesso em 01 mar 2017.

2. Almeida AMO, Santos MFS, Trindade ZA, organizadores. Teoria de representações sociais: 50 anos. Brasília (DF): Technopolitik; 2014. 3. Magnabosco-Martins CR, Camargo B, Biasus F. Representações sociais do idoso e da velhice de diferentes faixas etárias. Univ. Psychol. 2009; 8(3):831-47.

4. Melo VL, Cunha JOC, Falbo Neto GH. Maus tratos contra idosos no município de Camaragibe, Pernambuco. Rev. Bras. Saude Mater. Infant.[online] 2006; 6(supl.1):43-8.

5. Torres TL, Camargo BV, Boulsfield AB, Silva AO. Representações sociais e crenças normativas sobre envelhecimento. Ciênc. saúde coletiva. 2015; 20(12):3621-30.

6. Souza ER, Minayo MCS. Inserção do tema violência contra a pessoa idosa nas políticas públicas de atenção à saúde no Brasil. Ciênc. saúde coletiva. 2010; 15(6):2659-68.

7. Menezes MR, Alves MB, Souza AS, Silva VA, Silva EM, Oliveira CMS Comportamento agressivo na relação entre idoso e cuidador familiar em doenças demenciais. Cienc. cuid. saude. 2013; 12(4):744-51.

8. Silveira EAR, Luna GLM, Silva IZF, Moreira GAR, Saintrain MAVL, Vieira LJES. Notificação de violência contra idosos na atenção primária sob a ótica dos profissionais de saúde. In: Saintrain MAVL, Gondim APS, Silva VTBL, organizadores. O sistema único de saúde cuidando da pessoa idosa. Fortaleza (CE): EduECE; 2014. P.64-87. 9. Sousa DJ, White HJ, Soares LM, Nicolasi GT, Cintra FA, D'elboux MJ. Maus-tratos contra idosos: atualização de estudos brasileiros. Rev. Bras. Geriatr. Gerontol. 2010; 13(2):321-28.

10. Telles JL, Veras R, Goldfarb DC, debatedores. A construção das políticas públicas nos espaços democráticos de participação cidadã: a violência contra pessoas idosas na agenda do movimento social. Vida plena sem violência na maturidade: a busca contemporânea. Pensando nas origens da violência. Ciênc. saúde coletiva. 2010; 15(6):2669-76.

11. Valadares FC, Souza ER. Violência contra a pessoa idosa: análise de aspectos da atenção de saúde mental em cinco capitais brasileiras. Ciênc. saúde coletiva. 2010; 15(6):2763-74.

12. Wanderbroocke ACNS, Moré CLOO. Estrutura e funcionamento familiar e violência contra idosos. Psicol. Argum. 2013;31(74):395-403. 13. Krug EG, Mercy JA, Dahlberg LL, Zwi AB, Lozano R, editors. World report on violence and health. Geneva: World Health Organization; 2002. 14. Vieira KFL, Sousa DHAV, Lucena AR. A violência e suas repercussões na qualidade de vida das pessoas idosas. In: Formiga RIDM, organizador. Envelhecimento e longevidade: uma visão interdisciplinar. João Pessoa (PB): Moura Ramos Gráfica e Editora Ltda; 2014. p.93-125.

15. Pishchikoca L, Mamonova I. Victimization of persons late age. Geriatric Psychiatry; 2015; From the Serbsky National REsearch Centre for Social and Forensic Psychiatry; EPV15; 2015; Article 1425.

16. Brasil. Presidência da república. Subsecretaria de direitos humanos. Plano de ação para o Enfrentamento à violência contra a pessoa idosa. Subsecretaria de direitos humanos Brasília (DF); 2005. 17. Brasil. Secretaria de direitos humanos da presidência da república. (SDH/PR) Manual de enfrentamento à violência contra a pessoa idosa: é possível prevenir; é necessário superar. Texto de Maria Cecília Souza Minayo. Brasília (DF); 2013.

18. Wilson-Genderson M, Pruchno R. Effects of neighborhood violence and perceptions of neighborhood safety on depressive symptoms of older adults. Soc. sci. med. 2013; 85:43-9. 
19. Rusac S. Elderly abuse and alcohol consumption. Coll Antropol. 2015; 39(4):869-75.

20. Nóbrega SM. Sobre a teoria das representações sociais. In: Moreira ASP, Jesuíno JC, organizadores. Representações sociais: teoria e prática. João Pessoa (PB): Editora universitária UFPB; 2003.

21. Instituto Brasileiro de Geografia e Estatística (IBGE). Sinopse do censo. [Atualizada em 2010]. Acesso em 12 mar 2017. Disponível em: <http://www.ibge.gov.br>

22. Organização Mundial de Saúde. Relatório mundial sobre a prevenção da violência 2014. Traduzido por: Núcleo de estudos da violência da universidade de São Paulo. São Paulo; 2015.

23. Contarello A, Leone $\mathrm{G}$, Walchelke J. O envelhecimento em uma sociedade que envelhece. In: Tura LFR, Silva AO, organizadores. Envelhecimento e representações sociais. Rio de Janeiro: Quartet/ Faperj; 2012. p.139-68.

24. Gastrón L, Monchietti A, Oddone MJ. Representações sociais sobre homens e mulheres na velhice. In: Tura LFR, SILVA AO, organizadores. Envelhecimento e representações sociais. Rio de Janeiro: Quartet/Faperj; 2012. p.117-37.

25. Pereira FJC. Análise de dados qualitativos aplicados às representações sociais. In: Moreira ASP, Camargo BV, Jesuíno JC, Nóbrega SM. Perspectivas teórico-metodológicas em representações sociais. João Pessoa: Ed. Universitária; 2005. p.25-60.

26. Reis LA, Duarte SFP, Santos J, Reis LA, Gomes NP. Violência intrafamiliar contra o idoso: uma abordagem social. In: Reis LA, Santos J, Reis LA, Duarte SFP, organizadores. Ensaios sobre o envelhecimento. Vitória da Conquista (BA): Edições UESB; 2013. p.85-98.

27. Coler MAF. A violência contra idosos e suas representações sociais [tese de doutorado] Évora, Universidade de Évora; 2014 28. Moscovici S. A psicanálise, sua imagem e seu público. Petrópolis: Vozes; 2012.

29. Alves KL. Violência e maus-tratos contra a pessoa idosa: um estudo de representações sociais [dissertação de mestrado]. João Pessoa: Universidade Federal da Paraíba; 2016.

30. Ratinaud, P. (2009). IRAMUTEQ: Interface de R pourles analyses multidimensionnelles de textes et de questionnaires [computer software]. Recuperado em 5 março 2013. Disponível em: http:// www.iramuteq.org

31. Ratinaud P, Marchand P. Application de la méthode ALCESTE à de "gros" corpus et stabilité des "mondes lexicaux": analyse du "Cable Gate" avec IraMuTeQ. Actes des 11eme Journées internationales d'Analyse statistiquedes Données Textuelles;2012; Liège. JADT; 2012. p.835-44.

32. Camargo BV, Justo AM. IRaMuTeQ: um software gratuito para análise de dados textuais. Temas psicol. [online] 2013; 21(2):513-18. 33. Justo AM, Camargo BV. Estudos qualitativos e o uso de softwares para análises lexicais. X SIAT \& II SERPRO; 2014; UNIGRANRIO. Duque de Caxias: LAGERES/UNIGRANRIO; 2014.

34. Vieira de Souza JA, Freitas MCd, Almeida de Queiroz T. Violência contra os idosos: análise documental. Rev. bras. enferm. [Internet]. 2007; 60(3):268-272. Recuperado de: http://www. redalyc. org/articulo.oa?id=267019611004

35. Peixoto $C E$, organizador. Família e envelhecimento. Rio de Janeiro: Editora FGV, 2004.

36. Silva AO. Violência contra idosos em diferentes grupos etários: um estudo de representações sociais [projeto de pós-doutorado]. João Pessoa: Universidade Federal da Paraíba; 2014.

37. Silva CD, Gomes VLO, Oliveira DC, Amarijo CL, Acosta DF, Mota MS. Representação da violência doméstica contra mulheres entre profissionais de saúde: idade como atributo de diferenciação. Rev. enferm. UERJ. 2016; 24(3):e13212.

38. Bozzo ACB, Matos GC, Beraldi LP, Souza MD. Violência doméstica contra a mulher: caracterização dos casos notificados em um município do interior paulista. Rev. enferm. UERJ. 2017; 25:e11173. 